\title{
IMPRINTED POLYMERS IN ANALYTICAL CHEMISTRY
}

\author{
JOZEF LEHOTAY ${ }^{1}$, MIROSLAVA LACHOVÁ ${ }^{1}$, JÁN MOCÁK ${ }^{2}$ \\ ${ }^{1}$ Institute of Analytical Chemistry, Faculty of Chemical and Food Technology, Slovak \\ University of Technology, Radlinského 9, Bratislava, SK-812 37, Slovak Republic \\ (jozef.lehotay@stuba.sk) \\ ${ }^{2}$ Department of Chemistry, University of SS. Cyril and Methodius, J. Herdu 2, Trnava, \\ SK-917 01, Slovak Republic
}

\begin{abstract}
Molecularly imprinted polymers were prepared and tested in different way. 1-methyl-2piperidinoethylester of 4-decyloxyphenylcarbamic acid was used as template for imprints formation. Acrylamide, 4-vinylpyridine and methacrylic acid as monomers and methanol and acetonitrile as a porogene were used. Non-imprinted polymers (NIP) were prepared for each imprinted polymer by the same procedure. Polymers were employed as sorbents for solid-phase extraction (SPE). In this work the influence of polymerization mixture composition on polymer properties, such as capacity and selectivity, was investigated. The influence of alkoxy-chain length and position on benzene ring on the selectivity of polymers was also investigated.
\end{abstract}

Key words: HPLC, Molecularly imprinted polymer, SPE.

\section{Introduction}

Molecular imprinting is a technique for preparing chemically selective binding sites, which recognize a particular molecule, in a macroporous polymer matrix. The producing of molecularly imprinted polymers (MIPs) involves polymerization in solution of a target molecule (template) with functional and crosslinking monomers. Removal of the template molecule from a resultant polymer leaves behind specific recognition sites that are complementary to the template and enable the polymer to selectively rebind the imprint molecule from a mixture of closely related compounds. The MIPs can be produced in a covalent or non-covalent manner. In the case of covalent approach of molecular imprinting covalent bonds between the template and polymerizable monomers are formed. In order to remove the template from the polymer to liberate the binding sites, these covalent bonds have to be chemically cleaved. Non-covalent approaches are based on the formation of a prepolymerization complex between monomers and the template trough noncovalent bonds such as ionic interactions or hydrogen bonding. This enables the removal of the template simply by solvent extraction. Because MIPs have outstanding advantages such as predetermined selectivity, simple and convenient preparation, robustness in organic solvents and acidic or basic reagents, and durability to high temperature, molecular imprinting has drawn extensive attention in recent years (ZHANG et al., 2001). The advantages, applications and developments in molecular imprinting were mentioned in several reviews (KANDIMALLA and JU, 2004 CHAPUIS, 2006; RAMSTRÖM et al., 2001, ANDERSSON, 2000; ENSING and de BOER, 1999; HAUPT and MOSBACH, 1998). 
A technology, using selective solid phases based on MIPs in MISPE (molecularly imprinted SPE), is still investigated by research groups. Analysts can use two approaches to obtain the required selectivity: non-selective and selective adsorption of MIPs for SPE. If the analyte can be trapped on the MIP by ionic or hydrophobic interactions, users can load an aqueous sample directly and retain it by using nonselective interactions. If the trapping is performed in water, the non-selectively bound components will be removed by washing with organic solvent, and the analyte of interest retained on the MIP will switch from non-selective to selective binding (ENSING and MAJORS, 2002). MIPs have been already applied in biological, pharmaceutical (BERECZKI et al., 2001; THEODORIDIS and MANESIOTIS, 2002; XIE et al., 2003; FENG et al., 2004; CARO et al., 2004) and environmental analysis (BAGGIANI et al., 2001; MENA et al., 2002; CHAPUIS et al., 2003; ZHON and LAI, 2004). There are also some works where MISPE was used for sample preparation of herb or tea (XIE et al., 2001; BLAHOVA et al., 2004).

In this study, the influence of functional monomer and porogen, respectively, on the sorptive properties was investigated. The structurally related compounds (analytes with alkoxy-chain with in different position or with different length) were utilized to study the selectivity of MIPs. All MIPs were prepared by non-covalent approach by bulk polymerization and used as the sorbent for solid-phase extraction.

\section{Material and methods}

\subsection{Chemicals}

1-methyl-2-piperidinoethylesters of alkoxyphenylcarbamic acid (Fig. 1) were synthesized on Pharmaceutical Faculty in Bratislava. Acetonitrile, methanol, toluene, methacrylic acid and diethylamine were purchased from Merck, 4-vinylpyridine was obtained from Aldrich, acrylamide and azobisizobutylonitrile were obtained from Fluka, and acetic acid was purchased from Lachema.

(a)<smiles></smiles>

(b)<smiles>[R]Oc1cccc(NC(=O)OC(C)CN2CCCCC2)c1</smiles>

Fig. 1. Structure of compounds used in research, free base (a) and hydrochloride (b). Template molecule: $\mathrm{R}=$ - $\mathrm{C}_{10} \mathrm{H}_{21}$ in 4- position (4-DPCA). Other analytes used in research: $\mathrm{R}=-\mathrm{C}_{10} \mathrm{H}_{21}$ in 2- position (2-DPCA).

\subsection{HPLC analysis}

An HP 1100 system (Hewlett-Packard, Germany), consisting of a pump with a degasser, a diode-array detector (DAD) a $50 \mu$ injector and a HP ChemStation were used. Analyses were carried out on the analytical column Separon SGX C18 (125 x 4 $\mathrm{mm}, 7 \mu \mathrm{m})$ (Watrex, USA) at laboratory temperature. Mobile phase consisted of methanol, acetonitrile, acetic acid and diethylamine (80:20:0.1:0.1) at a flow rate of 
$0.5 \mathrm{ml} / \mathrm{min}$. Izokratic elution was used. Diode-array detector worked in the range of $190-400 \mathrm{~nm}$ and the chromatograms were acquired at wavelength of $240 \mathrm{~nm}$.

\subsection{Polymer preparation}

The molecularly imprinted polymer was prepared according to ZHANG et al. (2001) method. For synthesis of MIPs template (1-methyl-2-piperidinoethylester of 4decyloxyphenylcarbamic acid - 4-DPCA) was applied as hydrochloride and base, respectively. The base was used mainly for polymers prepared in acetonitrile and toluene because of better solubility of base template in these solvents. The composition of polymerization mixtures is shown in Table 1.

Table 1. Composition of polymerization mixtures.

\begin{tabular}{ccll}
\hline Polymer & $\begin{array}{c}\text { Form of template } \\
\text { molecule }\end{array}$ & Porogene & Monomer \\
\hline MIP1 & Base & Methanol & Acrylamide \\
MIP2 & Hydrochloride & Methanol & Acrylamide \\
NIP1,2 & - & Methanol & Acrylamide \\
\hline MIP3 & Base & Acetonitrile & Acrylamide \\
NIP3 & - & Acetonitrile & Acrylamide \\
\hline MIP4 & Base & Toluene & Acrylamide \\
NIP4 & - & Toluene & Acrylamide \\
\hline MIP5 & Hydrochloride & Methanol & 4-vinylpyridine \\
NIP5 & - & Methanol & 4-vinylpyridine \\
\hline MIP6 & Base & Acetonitrile & 4-vinylpyridine \\
NIP6 & - & Acetonitrile & 4-vinylpyridine \\
\hline MIP7 & Base & Toluene & 4-vinylpyridine \\
NIP7 & - & Toluene & 4-vinylpyridine \\
\hline MIP8 & Hydrochloride & Methanol & Methacrylic acid \\
MIP9 & Base & Methanol & Methacrylic acid \\
NIP8,9 & - & Methanol & Methacrylic acid \\
\hline MIP10 & Base & Acetonitrile & Methacrylic acid \\
NIP10 & - & Acetonitrile & Methacrylic acid \\
\hline MIP11 & Base & Toluene & Methacrylic acid \\
NIP11 & - & Toluene & Methacrylic acid \\
\hline
\end{tabular}

\subsection{Evaluation of MIP}

The cartridge capacity of each MIP and NIP was tested in methanol, acetonitrile, water and toluene. Prior to applying the solution of derivative of 4-DPCA, the polymer was pre-equilibrated with $5 \mathrm{ml}$ of methanol and then with $5 \mathrm{ml}$ of solvent in which the capacity was studied. 4-DPCA solution $(0.5 \mu \mathrm{g} / \mathrm{ml})$ was applied onto the cartridge (effluent was collected in $1 \mathrm{ml}$ fractions) until a release was detected. Each fraction was measured by HPLC. In the case of toluene, $5 \mathrm{ml}$ of 4-DPCA solution dissolved in toluene $(0.5 \mu \mathrm{g} / \mathrm{ml}$ in the case of MIP4, MIP7, NIP4 and NIP7;) was applied. In the case of MIP11 and NIP11, $20 \mathrm{ml}$ of 4-DPCA $(5 \mu \mathrm{g} / \mathrm{ml})$ was applied onto the 
cartridges. Then the cartridges were dried and the adsorbed analyte was desorbed by methanol - acetic acid mixture (95:5). Effluent was dried, resolved in methanol and measured by HPLC. For polymers'capacity, the template was used in the same form (free base or hydrochloride) as it was used during polymerization.

The selelectivity of MIP3, MIP 9, MIP10 and MIP11 for 1-methyl-2piperidinoethylester of 4-methoxyphenylcarbamic acid (4-MPCA) and 2decyloxyphenylcarbamic acid (2-DPCA) was tested. The selectivity of MIP3 and MIP11 in acetonitrile and MIP9 and MIP10 in methanol was determined. The procedure and the solution concentration were the same as described for 4-DPCA.

\section{Results and discussion}

\subsection{Capacity of polymers}

As it was described above, the capacities of MIPs were evaluated in different solvents. The same procedure was performed on MIPs and NIPs, respectively, and the resultant values of polymer capacities for template molecules are shown in Table 2.

Table 2. Binding capacities of prepared polymers. $\mathrm{RSD}=4.5-13.5 \%, \mathrm{n}=3$.

\begin{tabular}{cccc}
\hline Polymer & \multicolumn{2}{c}{ Capacity $(\mu \mathrm{g}$ of analyte/100 mg of polymer) } \\
\cline { 2 - 4 } & Acetonitrile & Methanol & Toluene \\
\hline MIP1 (AA-MeOH) & 0.1 & 0 & - \\
MIP2 & 0 & 0 & - \\
NIP1,2 & 0.1 & 0.1 & - \\
\hline MIP3 (AA-ACN) & 2.5 & 0.5 & - \\
NIP3 & $\mathbf{0 . 4}$ & 0.4 & - \\
\hline MIP4 (AA-Tol) & 0.7 & 0.1 & 0.9 \\
NIP4 & 0.5 & 0 & - \\
\hline MIP5 (4VP-MeOH) & 0.2 & 0.1 & - \\
NIP5 & 0.3 & 0 & - \\
\hline MIP6 (4VP-ACN) & 0.5 & 0.2 & - \\
NIP6 & 0.6 & 0 & 0.4 \\
\hline MIP7 (4VP-Tol) & 0.7 & 0.1 & - \\
NIP7 & 0.8 & 0.1 & - \\
\hline MIP8 (MAA-MeOH) & 3.8 & 2.0 & - \\
MIP9 & $\mathbf{2 8 . 0}$ & $\mathbf{8 . 0}$ & - \\
NIP8,9 & $\mathbf{4 . 0}$ & $\mathbf{1 . 9}$ & - \\
\hline MIP10 (MAA-ACN) & $\mathbf{2 0 . 4}$ & $\mathbf{2 0 . 2}$ & $\mathbf{6 1 . 1}$ \\
NIP10 & $\mathbf{1 0 . 7}$ & $\mathbf{5 . 9}$ & $\mathbf{6 . 6}$ \\
\hline MIP11 (MAA-Tol) & $\mathbf{7 6 . 0}$ & $\mathbf{3 2 . 0}$ & \\
NIP11 & $\mathbf{9 . 7}$ & & $\mathbf{6 . 2}$
\end{tabular}

$\mathrm{RSD}=4.5-9.5 \%, \mathrm{n}=3$.

Polymers prepared with hydrochloride form as a template were tested for both forms (hydrochloride and base, respectively) and the values of capacities of each polymer (MIP1, 5, 8) were similar for both forms of template. 
As it was mentioned in the introduction, the type of functional monomer and porogen plays important role during the formation of pre-polymerization complex. It is obvious from Table 2, that the specific capacity of polymers prepared with 4vinylpyridine as a functional monomer is very low. Therefore 4-vinylpyridine is not suitable monomer for this type of template. Methacrylic acid seems to be the most convenient monomer for our template. All MIPs, with the exception of MIP8, prove the ability to bind the template molecule specifically. Different capacity of MIP8 in comparison to MIP9 demonstrates the influence of the template form on the ability to form the pre-polymerization complex. The MIP9 was prepared using by the base form and the MIP8 was prepared with hydrochloride form.

When we compare the MIPs prepared with acrylamide, only MIP3 is able to bind the template specifically. It indicates the influence of porogene on the formation of pre-polymerization complex. Acetonitrile is less polar solvent in comparison to methanol. In this case less polar solvents optimize the interactions between monomer and template. More polar solvents such as methanol and water cancel the hydrogen bonding between monomer and template. The difference between acetonitrile and methanol is also in the way of creation of the hydrogen bonds - donor and acceptor.

The solvent used in the process of capacity determination is also very important. The nature of solvent employed for this step influences the relative swelling of the polymer. Swelling of the polymer causes changes in the binding site cavities. Solvent is also responsible to solvatation process. It means that the size and shape of template molecule depends on the solvent. Combination of these factors affects the change of capacity of MIP.

The highest values of binding capacities were obtained using water (not presented in Table) for sample loading for all MIPs and also for NIPs. The whole amount of loaded template $(100 \mu \mathrm{g})$ was sorbed onto the sorbents. In aquaeous environments, hydrogen-bonding and electrostatic interactions could be disrupted, and hydrophobic interactions, which are non-specific, could govern analyte retention (Haginaka 2005) This allows to use water samples for extraction, of course, after sample loading, the cartridge should be dried and washed with selective organic solvent able to disrupt the non-specific interaction of analyte with polymer.

\subsection{Capacity of MIPs for structurally related compounds}

The procedure of determination of capacity of MIP3, MIP9, MIP10 and MIP11 for structurally related compounds was the same as for template. The influence of length of alkoxy- chain on benzene ring was tested using by 4-MPCA. The influence of position of alkoxy-chain was investigated by measuring of MIPs' capacity for 2DPCA. The polymer capacities of MIPs and relevant NIPs are shown in Table 3.

As it is obvious from Table 3, the capacity of MIP3 is lower for analyte with shorter alkoxy-chain (4-MPCA) than for template. Therefore the length of alkoxychain impacts the capacity of analyte and MIP3 can recognize template molecule from structurally related compounds.

The influence of alkoxy chain position on benzene ring was also tested. The difference between capacity values of the template (4-DPCA) and the analyte with 
Table 3. Binding capacities of prepared polymers.

\begin{tabular}{cccc}
\hline & \multicolumn{2}{c}{ Capacity ( $\mu$ g of analyte/100 mg of polymer) } \\
\cline { 2 - 4 } & $\begin{array}{c}\text { Ester of p- } \\
\text { decyloxyphenylcarb. } \\
\text { acid (template) } \\
\text { 4DPCA }\end{array}$ & $\begin{array}{c}\text { Ester of p- } \\
\text { methoxyphenylcarb. } \\
\text { acid - 4MPCA }\end{array}$ & $\begin{array}{c}\text { Ester of o- } \\
\text { decyloxyphenylcarb. } \\
\text { Acid - 2DPCA }\end{array}$ \\
\hline MIP3 (AA-ACN) & 2.5 & $\mathbf{1 . 3}$ & 1.9 \\
NIP3 & 0.4 & 0.3 & 0.4 \\
\hline MIP9 (MAA-MeOH) & 8.0 & 9.2 & $\mathbf{4 . 8}$ \\
NIP8,9 & 1.9 & 1.9 & 1.8 \\
\hline MIP10 (MAA-ACN) & 20.2 & 18.1 & $\mathbf{1 0 . 2}$ \\
NIP10 & 5.9 & 3.2 & 6.2 \\
\hline MIP11 (MAA-Tol) & 76.0 & 75.1 & 76.2 \\
NIP11 & 9.7 & 10.2 & 8,0 \\
\hline
\end{tabular}

$\mathrm{RSD}=4.5-9.1 \%, \mathrm{n}=3$.

alkoxy chain in orto- position (2-DPCA) is not very leap. But in the case of MIP9 and MIP10, the capacity of MIPs is two times higher for template than for the analyte with alkoxy-chain in orto-position. It demonstrates that MIP9 and MIP10 have the different selectivity for compounds with decyloxy-group in other position on benzene ring.

\section{References}

ANDERSSON, L.I.: Molecular imprinting for drug bioanalysis: a review on the application of imprinted polymers to solid-phase extraction and binding assay. J. Chromatogr. B 2000, 739, 163-173.

BAGGIANI, C., GIOVANNOLI, C., ANFOSSI, L., TOZZI, C.: Molecularly imprinted solid-phase extraction sorbent for the clean-up of chlorinated phenoxyacids from aqueous samples. J. Chromatogr. A, 938, 2001, 35-44.

BERECZKI, A., TOLOKÁN, A., HORVAI, G., HORVÁTH, V., LANZA, F., HALL, A.J., SELLERGREN, B.: Determination of phenytoin in plasma by molecularly imprinted solid-phase extraction. J. Chromatogr. A, 930, 2001, 31-38.

BLAHOVÁ, E., LEHOTAY, J., SKAČÁNI, I.: The use of molecularly imprinted polymer for selective extraction of (+)-catechin. J. Liq. Chromatogr. Rel. Tech., 27, 2004, 2715-2731.

CARO, E., MARCÉ, R.M., CORMACK, P.A.G., SHERRINGTON, D.C., BORRUL, F.: A new molecularly imprinted polymer for the selective extraction of naproxen from urine samples by solid-phase extraction. J. Chromatogr. B, 813, 2004, 137143.

CHAPUIS, F., DICHON, V., LANZA, F., SELlERFGRE, S., HENNON, M.C.: Optimization of the class-selective extraction of triazines from aqueous samples using a molecularly imprinted polymer by a comprehensive approach of the retention mechanism. J. Chromatogr. A, 999, 2003, 23-33.

ENSING, K., DE BOER, T.: Tailor-made materials for tailor-made applications: application of molecular imprints in chemical analysis. Trends Anal. Chem., 18, 1999, 138-145. 
ENSING, K., MAJORS, R.E.: Selective sorbents for solid-phase extraction based on molecularly imprinted polymers. LC-GC Europe, 15, 2002, 16-25.

FENG, S.Y., LAI, E.P.C., DABAK-ZLOTORZYNSKA, E., SADEGHI, S.: Molecularly imprinted solid-phase extraction for the screening of antihyperglycemic biguanides. J. Chromatogr. A, 1027, 2004, 155-160.

HAGINAKA, J., Selectivity of affinity media in solid-phase extraction of analytes. Trends Anal. Chem. 2005, 24, 407-415.

HAUPT, K., MOSBACH, K.: Plastic antibodies: developments and applications. Trends Biotech., 16, 1998, 468-475.

KANDIMALLA, V.B., JU, H.: Molecular imprinting: a dynamic technique for diverse applications in analytical chemistry. Anal. Bioanal. Chem., 380, 2004, 587-605.

MENA, M.L., MARTÍNEZ-RUIZ, P., REVIEJO, A.J., PIZARRÓN, J.M.: Molecularly imprinted polymers for on-line preconcentration by solid phase extraction of pirimicarb in water samples. Anal. Chim. Acta, 451, 2002, 297-304.

RAMSTRÖM, O., SKUDAR, K., HAINES, J., PATEL, P., BRÜGGEMANN, O.: Food analyses using molecularly imprinted polymers. J. Agric. Food Chem., 49, 2001, 2105-2114.

THEODORIDIS, G., MANESIOTIS, P.: Selective solid-phase extraction sorbent for caffeine made by molecular imprinting. J. Chromatogr. A, 948, 2002, 163-169.

XIE, J., CHEN, L., LI, CH., XU, X.: Selective extraction of functional components derived from herb in plasma by using a molecularly imprinted polymer based on 2,2-bis(hydroxymethyl)butanol trimethacrylate. J. Chromatogr. B, 788, 2003, 233242.

XIE, J., ZLU, L., LUO, H., ZHON, L., LI, CH., XU, X.: Direct extraction of specific pharmacophoric flavonoids from gingko leaves using a molecularly imprinted polymer for quercetin. J. Chromatogr. A, 934, 2001, 1-11.

ZHANG, T., LIU, F., CHEN, W. WANG, J., LI, K.: Influence of intramolecular hydrogen bond of templates on molecular recognition of molecularly imprinted polymers. Anal. Chim. Acta, 450, 2001, 53-61.

ZHON, S.N., LAI, E.P.C., MILLER, J.D.: Analysis of wheat extracts for ochratoxin A by molecularly imprinted solid-phase extraction and pulsed elution. Anal. Bioanal. Chem., 378, 2004, 1903-1906. 